\title{
Rare Asymptomatic Presentation of Omental Mass from Cesarean Stitchline
}

\author{
Divya Pandey, Deepali Garg', Alpana Singh' \\ Department of Obstetrics and Gynecology, North Delhi Municipal Corporation Medical College and Hindu Rao Hospital, ' University College of \\ Medical Sciences and Guru Teg Bahadur Hospital, Delhi, India
}

\section{A B S T R A C T}

A case of big oozing lump of unknown origin through a healed cesarean section stitchline, completely asymptomatic at presentation, origin discovered as omentum on exploratory laparotomy came on $10^{\text {th }}$ postoperative day of an uneventful emergency surgery. This rare and silent presentation highlights the need to reconsider the practice of peritoneal nonclosure during cesarean section that has been adopted widely in recent past. It also calls for meticulous dissection and repair of rectus sheath during laparotomy.

KEY WORDS: Asymptomatic, cesarean section, peritoneal nonclosure, omental hernia

\section{INTRODUCTION}

In the past few decades, Obstetrics practice has seen a soar in the number of cesarean section and when a surgical practice is used worldwide, many changes are proposed and adopted in the conventional surgical approach.

Misgav Ladach technique have been very widely accepted nowadays involving single layer uterine closure, nonclosure of peritoneum and skin closure leading to significantly less time, reduced amount of bleeding, and suture material. ${ }^{[1]}$ However, a rare complication arising after adopting a new method, compels to reconsider and review the changes in conventional practice.

We present this rare and interesting case of an asymptomatic omental mass herniation through healed caesarean section stitchline after an uneventful surgery detected on $10^{\text {th }}$ postoperative day.

\section{CASE REPORT}

A 29-year-old third gravida (with two living issues) with previous two lower segment cesarean section (LSCS) at 39 weeks of gestation underwent emergency LSCS

\begin{tabular}{|l|l|}
\hline \multicolumn{2}{|c|}{ Access this article online } \\
\hline Quick Response Code & Website: \\
\hline & www.jbcrs.org \\
\cline { 2 - 2 } & \\
\hline
\end{tabular}

under spinal anesthesia for impending scar dehiscence. Emergency LSCS with bilateral tubal ligation was done via vertical midline incision and Misgav Ladach technique was used, that is, the uterus was closed in single continuous locking stitch and both visceral and parietal peritoneum were left open. Intraoperative and postoperative period was uneventful. Patient received antibiotic prophylaxis (intravenous ceftriaxone) for $48 \mathrm{~h}$ followed by oral antibiotics for 5 days. She was discharged on fourth postoperative day after change of dressing by the intern with usual follow up advices. She followed on tenth day for the stitch removal. She was completely asymptomatic with normal vitals and no bladder or bowel complaints except for one episode of vomiting on postoperative day 4 after discharge. There was no other significant history. On removing the dressing, a reddish pink fleshy mass with oozy surface of about $7.5 \times 5.5 \mathrm{~cm}$ was seen arising from stitchline. Abdomen was soft on palpation with normal bowel sounds. Local examination revealed a pink polypoidal mass protruding from mid-point of healed cesarean section stitchline with skin attached to the mass on all sides [Figure 1]. Besides upper and lower two stitches, which were embedded in the mass, all the remaining stitches were removed. Mass was painless, firm, with surface bleeding on touch.

Perplexed by the silent and interesting presentation of the patient with such a significant size mass, we sought surgeon's opinion and the patient was taken up for exploratory laparotomy.

Address for correspondence
Dr. Divya Pandey,
R-4/26, Rajnagar, Ghaziabad - 201 001, Uttar Pradesh, India.
E-mail: dr_devya1@yahoo.co.in


On opening stitchline, there was a defect in rectus sheath seen through which omentum was herniating [Figure 2] to form an organized mass covered with organized exudative substance, which bled on touch. The portion of omentum was separated and excised followed by parietal peritoneal closure. The anterior abdominal wall was closed in layers. Patient was discharged on day 7 after stitch removal with a healthy stitch line. Histopathology report confirmed the omentum with necrosed fat covered with granulation tissue.

\section{DISCUSSION}

This case was unique and discovered only at the time of stitch removal. The significant size, pinkish smooth surfaced lump with bleeding tendency, arising over such small duration (6 days), at first glance left us completely perplexed about its origin, which was revealed only at exploratory laparotomy and later confirmed histologically.

There are many possible operative techniques of cesarean section but depend largely on the clinical situation and the preference of the surgeon.

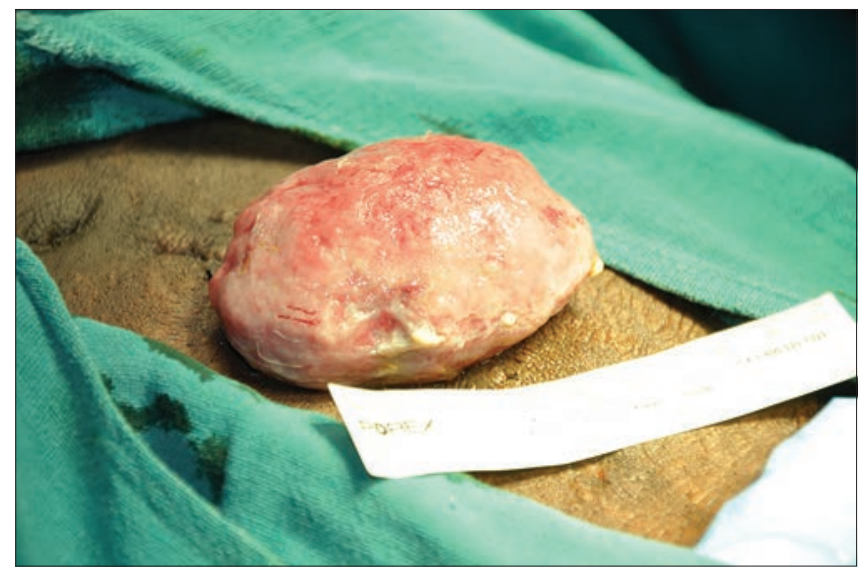

Figure 1: Mass sitting on the cesarean stitchline presenting on $10^{\text {th }}$ postoperative day

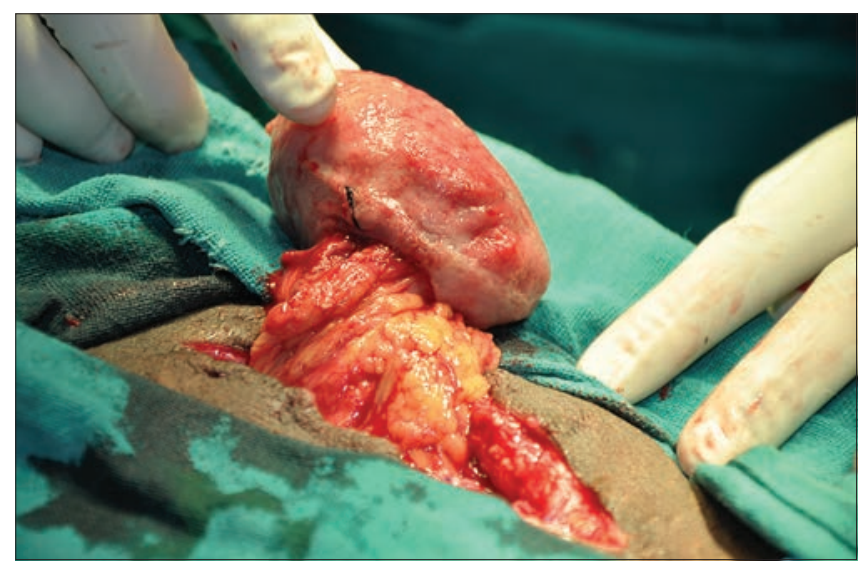

Figure 2: Mass arising from omentum through defect in rectus sheath
Peritoneal closure at laparotomy had been a 'standard' surgical practice. Reasons cited include restoration of anatomy, reducing infection by re-establishing anatomical barrier, preventing adhesion formation between intestines and fascia, between uterus and fascia and reducing wound infection, herniation, dehiscence and hematoma formation..$^{[2,3]}$ Spontaneous reperitonisation starts in 48-72 $\mathrm{h}$ with complete healing occurring in 5-7 days. This all the more favors the need of closure of the peritoneum at laparotomies. However, the Cochrane database systemic review showed that peritoneal nonclosure led to reduced operative time, less postoperative pain and fever, and shorter hospital stay. ${ }^{[4]}$

Extensive search of literature have shown only a few similar cases reported before. Two similar cases reported in literature of omental prolapse in cases of Misgav Ladach technique in 2004 and 2011 by Scholz et al., and Bhattacharya et al. reported, respectively, omental herniation in post LSCS case on days 7 and 15 were managed similarly like in our case with laparotomy. ${ }^{[5,6]}$ In other few cases, omentum was sutured between the edges of fascia recti..$^{77,8]}$

The mass might had been present earlier, which was probably missed by the intern during change of dressing. Probable explanation in our case is that during too much dissection of rectus sheath, owing to fibrosis due to previous surgeries, there was an inadvertent injury to the rectus sheath, which was probably left unrepaired, through which the omentum had protruded. The episode of vomiting leading to increased intra-abdominal pressure possibly became the precipitating factor. This possibly could have been prevented if parietal peritoneum was closed to provide an anatomical barrier.

These cases including our rare case suggest the possible importance of peritoneal closure in laparotomy cases so that complication like omental hernia can be avoided. The complication was due to repeat surgery on the scarred fibrosed tissue leading to the complication but possibly could have been prevented if the reinforcement of anterior abdominal wall was done with closure of peritoneum, which could have given it the strength in the period when natural re-epithelisation is not yet complete. Moreover, it also calls upon meticulous dissection and closure of the rectus sheath.

Matter of peritoneal closure or nonclosure at laparotomies had been a matter of debate since long. This case is just an example of a complication that could have been possibly prevented by peritoneal closure which could have reinforced the anterior abdominal wall in the period when natural re-epithelisation is not complete and is under process, which is $72 \mathrm{~h}$ to 7 days. 
Although just by one case we cannot say that the process of reperitonisation is necessary to be practiced in all laparotomies, but it calls for further prospective as well as retrospective studies in cases of hernias in immediate postoperative period to find out the cause and their preventive aspect.

\section{REFERENCES}

1. Studziński Z. The Misgav Ladach method of cesarean section compared to the pfannenstiel technique. Ginekol Pol 2002;73:627-6.

2. Bamigboye AA, Buchman E, Hofmeyr GJ. Closure of peritoneum at laparotomy: A survey of gynecology practice. S Afr Med J 1999;89:332-5.

3. Duffy DM, DiZerega GS. Is peritoneal closure necessary? Obstet Gynecol Surv 1994;49:817-22.

4. Bamigboye AA, Hofmeyr GJ. Closure versus non-closure of the peritoneum at Cesarean Section. Cochrane Database Syst Rev 2003;(4):CD000163.

5. Scholz HS, Petru E, Tamussino K, Winter R. Wound rupture after Misgav-Ladach Cesarean 5. Section; A case report. Gynakol Geburtshilfliche Rundsch 2004;44:238-9.

6. Bhattacharya S, Bhattacharyya SK, Alam H, Ghosh Roy S. Omental Evisceration after Cesarean Section: Safety of Peritoneal Nonclosure Technique. Case Rep Obstet Gynecol 2011;2011:205437.

7. Fournie A, Madzou S, Sentilhes L, Descamps P. Two observations of evisceration after caesarean section performed according to the so called Stark Procedure. Gynecol Obstet Fertil 2008;36:1211-3.

8. Das C, Chaudhuri S. Omental Herniation through umbilicus following Lower Segment Caesarean Section in Post Caesarean Pregnancy. British Journal of Medical Practitioners 2009;2009:48-9.

How to cite this article: Pandey D, Garg D, Singh A. Rare asymptomatic presentation of omental mass from cesarean stitchline. J Basic Clin Reprod Sci 2014;3:130-2.

Source of Support: Nil, Conflict of Interest: None declared 